\title{
An Evaluation of Web-based Homework (WBH) Delivery Systems: University of Sharjah Experience \\ http://dx.doi.org/10.3991/ijet.v8i4.2966
}

\author{
H.M. Elmehdi ${ }^{1}$, A. M. Ibrahim², U. A. Haba ${ }^{3}$ \\ ${ }^{1}$ University of Sharjah, Sharjah, United Arab Emirates \\ ${ }^{2}$ University of Manitoba, Winnipeg, MB, Canada \\ ${ }^{3}$ Coventry University, Coventry, United Kingdom
}

\begin{abstract}
The objective of this paper is to investigate the effectiveness of the Web-Based Homework (WBH) systems on the performance of University of Sharjah (UAE) students. We have investigated:

1) student perceptions and acceptability of WBH systems;

2) compare the students' performance in homework assignments conducted using WBH systems and conventional paper-based homework approaches.

Among the students surveyed, 53\% preferred WBH systems to the conventional paper-based approach. In addition, $57 \%$ of the students felt the WBH system helped them improve their performance in the course. It was also found that students scored higher in homework assignments delivered via the WBH system (by about 17\%). The advantages brought by WBH systems appear to motivate students and help improve their performance. It was also found that students' maturity plays an important role in accepting the WBH system, where it was evident freshmen college students strongly opposed the use of WBH systems.
\end{abstract}

Index Terms - Education Quality, Freshmen Students, general Physics, Students' Performance, Web-Based Homework System.

\section{INTRODUCTION}

The educational community is witnessing a rapid increase in the use of Web-Based (WB) tools in teaching and learning. Besides their educational advantages, the increasing popularity of WB tools provides means to help instructors cope with the increase in class size and heavy teaching load. This is especially useful at universities were student tuition is the main source of income, where large class sizes is common [1,2]. One tool in particular that has gained more attention lately is the Web-Based Homework management system (WBH), which offers instructors a digital mean by which they can assign homework problems over the internet [3,4,5]. Major textbook publishers, such as Person and John Wiley and Sons Inc., are constantly developing WBH systems for their textbooks used in universities and colleges as well as in high schools. Mastering Physics (Pearson) and WileyPlus (John Wiley) are considered the two leading WBH systems available in the market today; at least as far as elementary physics courses are concerned.

Web Based Homework (WBH) systems are a form of an adaptive media used to support the teaching and learning process in educational institutions. They are best defined as an interactive web page that is available in cyber space for which students $\log$ on to via the Internet using an assigned user id and password [6,7].

The course page contains several tools aimed at facilitating homework delivery via the Internet. The publisher manages and maintains the website, for which instructors can obtain access to it, and can create course pages for each course they teach. To gain access to the course page, students must purchase a digital code along with their textbook. Instructors can enrol students to the respective sections. The course page has different dashboards for students and instructors. The students dashboard features tabs for Home, Read, Study \& Practice, Assignment, and Gradebook. It also includes various external links, animations and various educational movies. The instructor's dashboard features additional tabs such as Course Admin, Class Info, and Prepare\& Present and other tabs for assigning and managing homewok assignments and online quizzes. In addition, the student website allows access to an HTML copy of the textbook, the assignments made available by the instructor, and they can view their grades on the gradebook. Students can also read instructor's announcements as well as the system announcements. Students can view and download documents created by the instructor. The featured electronic version of the physics textbook is organized in chapters, but has additional teaching and learning tools such as audio and video presentations, simulations, review problems and solutions of selected problems. The assignments feature problems selected by the instructor, for which the due date may be set. Instructors can also allow printing of individual problems or the full assignment so that students may have the option to work through the exercises while seated away on their favorite setting. When creating assignments, instructors can select from the end-of-chapter problems, test bank problems. Instructors have the option of creating their own homework problems. For courses with multiple instructors, the system allows them to share the assignments and other information related to the course. The curse page allows the inclusion of videos, animations 
(as hints) and simulations. Answers could be multiple choice, text entry of the final numerical answer, entering a symbolic (algebraic) answer, typing in a word or short essay, or uploading a file. Assigned problems are classified in accordance to difficulty level, i.e. hard, medium, or easy. In addition to setting the deadline, instructors can set the weight for each questions, number of attempts allowed and penalty for overdue assignments. While the students are solving questions, the system offers online hints, such as the relevant sections in the chapter and the formulae they may need. In many cases, the numerical exercises are randomized, so each student assignment has a unique set of numbers.

Instructors can setup problems so that students get immediate feedback and they can allow multiple attempts to a problem. As mentioned above, the instructor handles the administrative details, create assignments and questions, and review or download student scores and responses. The system also has additional features such as chat rooms, instructor notes, calendars, and other features available for both instructors and students, all of which aim at promoting instructor-student interactions.

From the instructor's prospective, there are several advantages to WBH systems that will contribute not only to improve teaching and learning, but also to help with administrative and statistical records as well. For example, WBH systems offer detailed records of the grades in an excel-like worksheet, which includes, in addition to the grades, the time taken by each student to solve each problem, and all statistical parameters, i.e. mean, max, min, etc. (Information was taken from WileyPlus Guide to Students Available online).

There are several advantages to the use of WBH systems over the conventional paper-based homework (PBH) approach, where students are given homework problems on paper, which they take home to solve and bring it back on a pre-set deadline. These papers are then collected, graded and a group feedback is often given to the students in the form handwritten key answers or discussions. These advantages include $[1,8,9,10]$ :

- Students receive immediate feedback, where the student grades are posted upon submission of the answer.

- Students are provided with hints for every question, where WBH systems such as WileyPlus provide students with step-by-step hints leading to the answer of each question.

- Feedback is provided to students individually, where every student learns his or her mistakes after going over the answer.

- The WBH system tends to save instructors the time they spend in grading, recording, and communicating the grades to the students. For example, WileyPlus grades and records the students' scores and makes them available for downloading or exporting by the instructor.

- In addition, time and Dirhams will be saved in copying, distributing, collecting, sorting, and filing of the paper-based homework.
- Other Web-Based teaching and learning advantages include availability of the homework, accessibility and ability to solve the homework anywhere.

- WBH provides students with 24/7 interaction with the instructor either via email or via discussion forums.

The Applied Physics department at the University of Sharjah has been using WBH since the Fall Semester of the academic year of 2008-2009. In the following academic year, the department decided to expand this experience to include the students of the "Foundation Year" of the Medical Colleges. The numbers of students in these classes tend to be very large and the number of sections is usually over ten. The Applied Physics Department's decision to experiment with WBH systems was initially launched in response to the university's decision to increase class sizes, the heavy teaching load and the unavailability of teaching Assistants (TAs), for grading homework assignments, quizzes and various class activities. The inclusion of WBH in teaching and learning is new, not only to the University of Sharjah, but also to the region as well, where a very limited number of institutions have introduced WBH systems to assist in teaching and learning. Like any new teaching and learning approach, questions and concerns were raised about its effectiveness and role in improving the quality of education, achieving the proposed course outcomes, as well as students' perception, acceptance and attitude towards such a new teaching and learning method $[11,12]$. In addition, technical issues such as availability of internet to all students at home, internet speed and bandwidth have been considered as limiting factors in adopting $\mathrm{WBH}$ in postsecondary institutions in developing countries such as the UAE [13,14]. These concerns and questions can be summarized in the following points:

- Do students spend less time on WBH than on $\mathrm{PPH}$, which means that they are spending less time practising concepts? This can be measured by counting the time students spend each week answering questions and/or solvingproblems in each approach.

- What is (are) the students' attitudes towards and their acceptance of the WBH? (i.e. which approach do they prefer? Do students really prefer to receive immediate feedback?)

- Where do students access the web to complete online assignments? On campus? At home? In an Internet cafe'?

- Are technical problems (connectivity, accessibility, internet speed, etc.) have an impact on the effectiveness of WBH systems? Also, are these technical issues tend to put some students at a disadvantage?

- Does grade automation and immediate feedback reduce the interaction between students and instructors? 
- $\quad$ Are the tools provided by the WBH systems, including exercise hints, multiple attempts, immediate feedback are enhancing learning and assisting students to better understand the material or are they narrowing the students' horizons, ability to think, and making them dependent on hints and guidelines?

- Do multiple attempts and immediate feedback motivate students to attempt more exercises?

- Are the accessories provided on the WBH page (animations, videos, test banks and external links) helpful?

- Do students like the e-textbook provided with the WBH page or do they prefer a paper text? Does this discourage students from reading the textbook and the extra information provided in the textbook?

- Do students prefer the WBH grading system, where questions are graded based on the exact numerical answer, or do they prefer the conventional grading system where partial grades are usually given for partial solutions.

- Are there any gender, age, and student level differences resulting from implementing the WBH?

A review of the literature reveals that no conclusive answers to these questions have been provided (see for example References $[1,2,3,4,5,8,9,10,13,14]$. In fact, some researchers suggested that the answer may vary from region to region, depending on demographic and or cultural background, which in some cases are driven mainly by how society values education $[10,15]$. To our knowledge, no research has been found that addresses these issues, in the Gulf and Middle East regions. This makes results reported in this paper the first to present an evaluation of WBH systems for this part of the world.

The WBH system investigated in this paper is WileyPlus (product of John Wiley and Sons Inc.). Another study on another WBH system, Mastering Physics (product of Pearson) is currently underway and the results will soon be published. As it will be discussed in more detail later in the materials and methods section, our study include online survey questionnaires, comparison exercises, and discussions of the effectiveness of WBH systems on education attributes, especially those related to improving education quality. In addition, the study aims to gauge students' perception and attitude towards WBH system and the impact and role it has in improving students' understanding of the material and ultimately help them achieve higher grades in the course, and achieve the desired course outcomes. Subjects included in the study were comprised of students enrolled in Physics for Medical Sciences. The later is an algebra-based introductory physics course offered in the Foundation Year of the Medical Colleges, (Dentistry, Medicine and Pharmacy) at the University of Sharjah, UAE, as part of their curriculum.

\section{Materials AND Methods}

As mentioned above, the subjects investigated in this study included first year students enrolled in the Foundation Year of the Medical Colleges at the University of Sharjah (UoS). These students have attained high grades in High School Physics as required by the admittance criteria of the Medical Colleges, which requires students to get a minimum score of $85 \%$ on their high school physics. Among the courses Foundation Year students have to take is the 3-credit-hour algebra-based Introductory Physics course called "Physics for Medical Sciences". The department of Applied Physics has introduced $\mathrm{WBH}$ systems to improve teaching and learning and to deal with the increase in class sizes and heavy teaching load. WileyPlus is one of the leading WBH systems, where it was reported on their website that the system is used by over 1 Million students worldwide [16]. Our methodology included a survey questionnaire comprised of thirteen (13) questions, which included questions aimed at gauging the student perception and/or acceptance of WileyPlus as WBH system. The survey also included questions aimed at gauging the impact of employing IT teaching and learning tools on the performance of students. The survey was conducted online using open source Google Forms, which enabled us to conduct the survey and collect the results in table or graph format. Students were requested to enter their unique University of Sharjah ID number. This cautionary step was introduced to ensure that only students enrolled in the course are counted. Students were advised that the survey is part of the ongoing evaluation of the WileyPlus system and it will not affect their activity grade. In total, 224 students responded to survey questions, before the 3day deadline. These comprised about $87 \%$ of the students enrolled in Physics for Medical Sciences. The remaining students who did not take part in the study were those who decided to take the course in the following semesters.

In addition to the online survey, several in-class exercises were conducted. These exercises aimed at comparing the performance of students in homework assignments done by using WileyPlus WBH systems and using the conventional Paper-Based approach. Students were first given the assignment on WileyPlus, under normal conditions, which included one week due date, multiple attempts, and the usual hints, and immediate feedback provided by the WileyPlus system. At the same time, a second selected group of homework problems, which were very similar to the ones assigned on the WileyPlus system, were assigned to the students using the conventional Paper-Based approach. The results (grades attained) of the two assignments were then compared to assess the performance of the students in each approach. After the two sets of grades were collected, students were asked to compare the two approaches and which one they preferred. The survey was conducted 5 weeks into the semester after the students got acquainted with the system and after they have finished three assignments using the system. 


\section{RESULTS AND DISCUSSION}

\section{A. Survey Results}

Two hundred and twenty (224) students answered the survey questionnaire. These students enrolled in various sections of the same course. Table 1 shows the gender and discipline distribution of the respondents. The gender gap among the students surveyed is compatible with the female-male ratio of the Medical Sciences Colleges, where male students count for approximately $18 \%$ of the total number of the students.

TABLE I.

SUMMARY OF THE SURVEYED STUDENTS

\begin{tabular}{|l|l|l|}
\hline \multirow{2}{*}{ Gender } & Male & $13 \%$ \\
\cline { 2 - 3 } & Female & $87 \%$ \\
\hline \multirow{3}{*}{ College } & Dentistry & $84(38 \%)$ \\
\cline { 2 - 3 } & Medicine & $103(46 \%)$ \\
\cline { 2 - 3 } & Pharmacy & $37(16 \%)$ \\
\hline
\end{tabular}

Among these students responded to the survey, only two (2) students were enrolled in the class but did not use WileyPlus as a WBH system. These were students who were planning to drop the course and they are attending the classes until the withdrawal application has been processed. These students were excluded from the subsequent analysis and discussion since they were not exposed to the WileyPlus course page to evaluate it.

The first set of questions dealt with system accessibility and ease of navigation. More than $85 \%$ of the students found the system easy to navigate and said they did not experience any technical difficulties logging onto the course page. When students were asked about the convenience of the WileyPlus system, and their ability to answer the questions with relative ease, $53 \%$ felt that the system is very convenient and they did not encounter any difficulty while answering questions. The remaining $47 \%$ felt that the new experience of reporting only the final numerical answer for the questions, without including the details of the solution, does not allow them to discuss their wrong answers with the instructor later, especially if they felt that they have followed the correct approach to solve the problem. Others indicated that doing the homework on the computer screen rather than on paper was a bit inconvenient, especially for those who did not own their own laptop computers.

Next, students were asked the following two questions:

1) Do you prefer WileyPlus WBH system to the traditional Paper-Pencil approach?

2) Do you think you will score higher grades had you submitted your homework using the traditional paper-pencil approach?

The students' responses to this question are shown in Fig. 1. It is evident from Fig. 1. that students are split between the two approaches, with about $57 \%$ of the students interviewed felt that they enjoy the WileyPlus system, while the remaining $43 \%$ think that they can perform much better using the traditional approach. For the students who felt they would perform better using WBH system, the hint system provided by WileyPlus course page was the main reason behind their belief that they will perform better. The hint system provides students with specific hints for each question, which refers them to the proper section and the formula they should use to solve that question. On the other hand, the other group of students felt that the WBH system did not promote group discussions and the fact that they could not report the details of their answer, especially for questions, which they could not give complete answers to and felt they can possibly claim partial credit for. In addition, these students felt that such approach limits their study habits; since they only need to study the section related to the question. While in the conventional approach, they would survey more material across the chapters with obvious side benefits. Students also felt that WBH system decreased their interaction with the instructor, because they relied more on the hints provided in the course page.

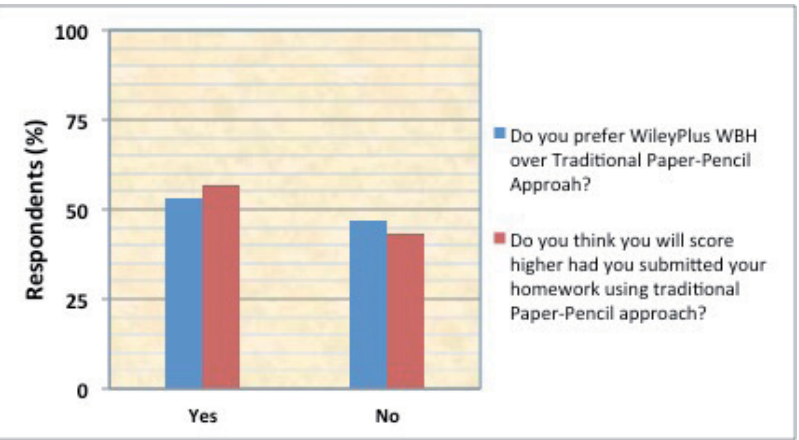

Figure 1. Students' responses to questions nine and ten.

In a follow up question, students were asked if they would like to take more homework problems assigned via the WileyPlus course page, $31 \%$ of the students responded with "yes, all the time", 49\% said "yes, occasionally", while only $16 \%$, who did "not at all" like to take any more assignment on the WileyPlus system. The percentage of students who did not like instructors to use the system anymore may be considered small; especially since this is the first time the system has been implemented.

The last three questions in the survey asked the students to list the advantages and disadvantages of the WileyPlus WBH system. The answers to these questions are grouped in the Table 2. As it can be seen from Table 2 some points which were reported by some students as advantages were reported by other students as disadvantages. An example of this is the instructor's role, where a group of students felt that the WBH systems limited their interaction with the instructor, depriving them from getting hints, comments, and general feedback from the instructor. On the other hand, the second group of students listed these points as advantages, they felt that they do not have to rely on the instructor's help when they get stuck. 
TABLE II.

THE ADVANATGE AND DISADVANTAGES OF WHB IN VIEW OF THE UNIVERSITY OF SHARJAH FOUNDATION YEAR STUDNETS

\begin{tabular}{|c|c|}
\hline Disadvantages & Advantages \\
\hline $\begin{array}{l}\text { The fact that the solution has to } \\
\text { be reported in the form of a final } \\
\text { single numerical answer, which } \\
\text { sometimes includes reporting } \\
\text { exact significant figures. }\end{array}$ & $\begin{array}{l}\text { Can solve the HW anywhere, so } \\
\text { long there is an internet } \\
\text { connection and there is no need } \\
\text { to carry the textbook around. }\end{array}$ \\
\hline $\begin{array}{l}\text { One needs internet connection } \\
\text { with adequate speed at home and } \\
\text { at work. Some students reported } \\
\text { that they do not have internet at } \\
\text { home, which meant they could do } \\
\text { the homework while they are at } \\
\text { school. }\end{array}$ & $\begin{array}{l}\text { Gives the student an immediate } \\
\text { feedback on their answers. }\end{array}$ \\
\hline $\begin{array}{l}\text { Technical difficulties, especially } \\
\text { those related to "timing out", } \\
\text { occasional login problems and } \\
\text { slow connections. }\end{array}$ & $\begin{array}{l}\text { The hints the system provides are } \\
\text { great guide for the solution, and } \\
\text { knowing exactly which section to } \\
\text { read and formulae to use in the } \\
\text { solution. }\end{array}$ \\
\hline $\begin{array}{l}\text { The limited number of attempts is } \\
\text { frustrating, especially since the } \\
\text { parameters change if the students } \\
\text { logs out of the system. }\end{array}$ & $\begin{array}{l}\text { It gives students the opportunity } \\
\text { to use the most advanced digital } \\
\text { and e-teaching and learning } \\
\text { approaches and tools. }\end{array}$ \\
\hline $\begin{array}{l}\text { WileyPlus grades the problems } \\
\text { based on the final answer, and } \\
\text { does not take into account the } \\
\text { solution steps for partial credit. }\end{array}$ & $\begin{array}{l}\text { The approach is well organized } \\
\text { and students do not have to be in } \\
\text { class to get a copy of the } \\
\text { homework. }\end{array}$ \\
\hline $\begin{array}{l}\text { The time taken to finish the } \\
\text { solution is longer, because } \\
\text { students have to first figure out } \\
\text { the answer and then report it. }\end{array}$ & $\begin{array}{l}\text { The approach motivates the } \\
\text { students to work harder, } \\
\text { especially since the answer is } \\
\text { given immediately upon } \\
\text { submission, and if you get it } \\
\text { wrong the first time, it gives } \\
\text { more chances, which means you } \\
\text { try different approach to solve } \\
\text { the problem, i.e. learn more. }\end{array}$ \\
\hline $\begin{array}{l}\text { It is not easy to scroll through the } \\
\text { digital textbook }\end{array}$ & $\begin{array}{l}\text { Students feel happier and } \\
\text { motivated when they get their } \\
\text { result immediately. }\end{array}$ \\
\hline $\begin{array}{l}\text { Having to read and solve the } \\
\text { questions on the computer screen } \\
\text { requires students to stare at the } \\
\text { computer screen for extended } \\
\text { periods of time, which may be a } \\
\text { health hazard. }\end{array}$ & $\begin{array}{l}\text { Students do not have to depend } \\
\text { on the instructor to give them } \\
\text { hints on how to solve the } \\
\text { homework problems. }\end{array}$ \\
\hline \multirow[t]{2}{*}{$\begin{array}{l}\text { No teacher feedback, i.e. no } \\
\text { comments or notes on our work } \\
\text { since only the final answer is } \\
\text { reported. }\end{array}$} & $\begin{array}{l}\text { The system provides other tools } \\
\text { and resources such as } \\
\text { simulations, videos, images and } \\
\text { extra-solved exercises. }\end{array}$ \\
\hline & $\begin{array}{l}\text { It made physics more fun and } \\
\text { enjoyable. }\end{array}$ \\
\hline
\end{tabular}

\section{B. Comparative Exercises}

Next, we conducted a comparative exercise aimed at comparing the performance of the students using the two homework delivery approaches. The students were given two homework assignments; the first of which included a set of problems, which were photocopied and given to the students on a paper and asked to solve these problems at home and return them before the proposed deadline. The second assignment included a second set of problems assigned via the WileyPlus course page. The problems were very similar and covered the same material. Both assignments were graded and the performance of the students was compared based on the grades they have attained in both assignments. The results are shown in the Figure 2.

Figure 2 shows that the students' scores were lower on paper-based approach than the WBH approach, with the class average dropping from $76 \%$ to $50 \%$. Reasons for such drop may be attributed to the availability of the online and direct hint system, which guided the students to the solution or narrowed down the material or formulae needed to solve that problem to one section, which often times contain similar or related questions as solved examples.

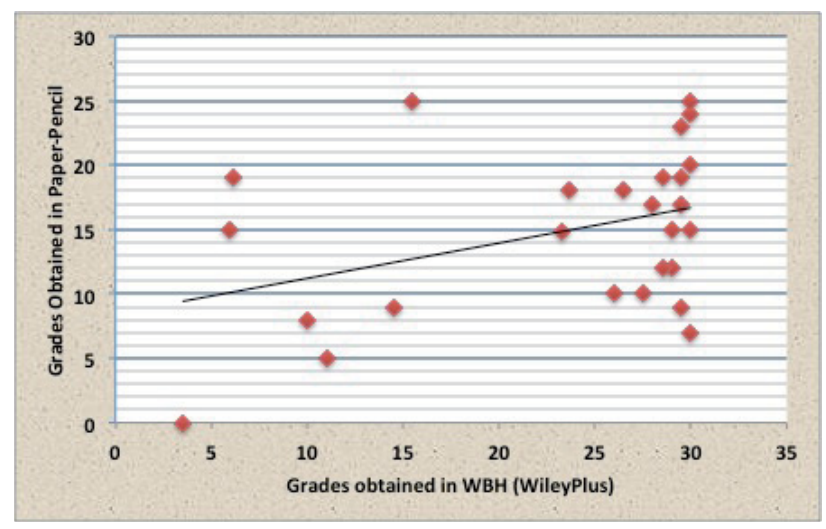

Figure 2. Correlation between the grades obtained by the students using the two homework approaches.

Even with these results, which indicate that WBH systems tend to improve the performance of students, it remains debatable as to which approach has more effect on the students' grasp of the material and prepares them better for the exams. On the one hand, one may argue that using WBH systems tend to limit the students' exposure, since they will be searching for the specific formulae and section to solve the problem at hand. A counter argument will emphasize that fact that such approach will help students focus and save them time and effort. The same argument-counter-argument may be raised for all other concerns or advantages/disadvantages, which raised earlier in the introduction section and in Table 2, by the students, while answering the survey.

It is worth pointing out that there was no noticeable change in performance of the students in the course (average final grades or the course passing percentage) after the WBH system has been implemented. It should also be pointed out that the system has been employed for a few semesters at the time of this study, hence to reach conclusive evidence, the performance of the students needs to be followed over a number of semesters. In comparison to similar studies, the results obtained in this study were found to reach the same conclusion as that of Ref. [10], who found that the performance of Turkish students in assignments conducted using WBH was $10 \%$ higher than when they solved the problems using the conventional approach.

\section{CONCLUSION}

The results of this study, which was conducted at the Applied Physics Department, University of Sharjah, 
United Arab Emirates, aimed at investigating the influence of WebBased Homework (WBH) delivery systems on the performance of students in Introductory Physics Courses, was presented. The WBH systems investigated in this study was WileyPlus; a WBH course page that accompanies the Physics textbook by Cutnell and Johnson, assigned to foundation year students at the medical college. The study was comprised of a survey questionnaire and comparative exercises that were conducted deep into the semester after the students got acquainted with the WBH system. The results indicate that the students were split between the two homework delivery approaches; where 53\% preferred WBH system to the conventional paper-based homework system. In addition, $57 \%$ of the students interviewed believed that they would score better marks on the WBH assignments. These students also felt that the WBH system will help them better understand the material. When the performances of the students in the two approaches were compared, it was found that students performed much better in the WileyPlus assignments, where the class average was about $16 \%$.

There is no doubt the WBH system has met its objectives from the instructors' point of view, especially in dealing with the time consuming tasks associated with conducting homework assignments using the conventional paperbased approach for large classes and multi-sections. From the students' point of view, the advantages of having online help and immediate feedback are the top two advantages for the WBH systems. Technical difficulties and issues related to Internet access were legitimate concerns for students. In conclusion, the WBH systems have great potential to improve the quality of education in our post secondary institutions and facilitate the teaching and learning process, thereby utilizing the readily available IT tools for the instructors and students. Issues like student maturity and awareness of the advantages of such WBH systems needs to be highlighted.

\section{ACKNOWLEDGMENT}

The authors would like to that the University of Sharjah for funding this project. The authors would also like to thank the students who took part in this study.

\section{REFERENCES}

[1] R. Dufresne, J. M. Mestre, M.D. Hart and K.A. Rath, "The Effect of Web-Based Homework on Test Performance in Large Enrolment Introductory Physics Courses", Journal of Computers in Mathematics and Science Teaching, 21(3), pp. 229-251, 2002.

[2] S. R. Hatfield and K. L. Gorman, "Assessment in education-the past, present, and future. In J. Rucker (Ed.)", Assessment in business educational national business education association yearbook, No. 38 (pp. 1-10). Reston, VA: National Business Education Association, 2000.
[3] S. W. Bonham, D.L. Deardorff and R. J. Beichner, "Comparison of student performance using web and paper-based homework in college-level physics", Journal of Research in Science Teaching, 40, pp. 1050-1071, 2003. http://dx.doi.org/10.1002/tea.10120

[4] T. Stelzer and G. Gladding, "The Evolution of Web-based Activities in Physics at Illinois". Forum on Education of The American Physical Society. Available online at: http://www.aps.org/units/fed/newsletters/fall2001/stelzer.html, 2001.

[5] G. H. Nail, "PH Grade Assist: Homework in the twenty-first century", Proceedings of the 2006 ASEE Southeast Section Conference, 2006.

[6] F. Lee and R. Heyworth, "Electronic homework". Paper presented at the annual meeting of the American Educational Research Association, Chicago. (ERIC Document Reproduction Service No. D405859), 1997.

[7] J.E. Bartlett, K.A. Reynolds and M. W. Alexander, "A tool for online learning”, Journal of Online Learning, 11(3\&4), pp. 22-24, 2000.

[8] D. Laurillard, "Rethinking university teaching: A conversational framework for the effective use of learning technologies" (2nd ed). London, Routledge, 2002, pp. 312-331. http://dx.doi.org/10.4324/9780203304846

[9] E. Altun, "6th, 7th and 8th Graders' Attitudes towards Online Homework Assignment Sites", The Turkish Online Journal of Educational Technology, 7 (4), 5-18-(retrieved on Dec 15, 2010): URL: http://www.tojet.net/articles/741.pdf.

[10] N. Demirci, "University students' perceptions of web-based vs. paper-based homework in a general physics course", Eurasia Journal of Mathematics, Science \& Technology Education, 3(1), pp. 29-34, 2007.

[11] L. Cao and B. Golden, "Web-based agents for reengineering engineering education", J. Educational Computing Research, 23, 4, pp. 421-430, 2000.

[12] H. Cooper, J. J. Lindsay, B. Nye and S. Greathouse, "Relationships among attitudes about homework, amount of homework assigned and completed, and student achievement", Journal of Educational Psychology, 90(1), pp. 70-83, 1998. http://dx.doi.org/10.1037/0022-0663.90.1.70

[13] J. Dash, "Computerware introduces remotely hosted software for Internet testing service", Computenvorld, 34 (88), pp. 1- 4, 2000.

[14] S. R. Hiltz, "Evaluating the virtual classroom". In LM Harasim (ed.) Online Education: Perspectives on a New Environment, Praeger, New York, 2000, pp. 133-184.

[15] D. P. Maloney, "Research on problem solving: Physics". In Gabel, D.L. (Ed.), Handbook of research on science teaching and learning, New York: Macmillan, 1994, pp. 559.

[16] WileyPlus Guide to Students. Available at: http://www.wiley.com/college/egradeplus/help_docs/student_help 2.pdf

\section{AUTHORS}

H. M. Elmehdi is with University of Sharjah, Sharjah, United Arab Emirates.

A. M. Ibrahim is with University of Manitoba, Winnipeg, MB, Canada.

U. A. Haba is with Coventry University, Coventry, United Kingdom.

Submitted 30 June 2913. Published as re-submitted by the authors 8 August 2013. 